\title{
EPR Spectra of the Genuine-Organic and Metal-Organic TCNQ-Based Anion Radical Salts
}

\author{
M. BotKo*, E. ČižMÁr, M. KAJŇAKOvá, A. FEHER \\ Institute of Physics, Faculty of Science, P. J. Šafárik University, Park Angelinum 9, 04154 Košice, Slovakia

\begin{abstract}
We have measured the electron paramagnetic resonance spectra of genuine-organic anion-radical salts [Me-2,6di-Me-Py](TCNQ) $)_{2}$, [Me-3,5-di-Me-Py](TCNQ $)_{2}$, [N-Me-OH-Me-Py](TCNQ $)_{2}$, [N-Et-OH-Me-Py](TCNQ) ${ }_{2}$, and metal-organic anion-radical salt $\left[\mathrm{Mn}-\mathrm{phen}_{3}\right](\mathrm{TCNQ})_{2} \cdot \mathrm{H}_{2} \mathrm{O}$ in the temperature range from $2 \mathrm{~K}$ to $300 \mathrm{~K}$ in the $\mathrm{X}$-band frequency range. A comparison study of the shape of spectra, $g$-factors and linewidths with respect to the composition and crystal structure of studied compounds is presented. While the genuine-organic anion-radical salts display a typical EPR response originating from TCNQ pairs, the spectra of metal-organic anion-radical salt are dominated by the contribution of transition metal.
\end{abstract}

DOI: 10.12693/APhysPolA.126.252

PACS: 75.50.Xx, 76.30.- $\mathrm{v}$

\section{Introduction}

Ever since their discovery, the organic anion-radical charge-transfer complexes have attracted significant interest thanks to the variety of their physical properties. Some of the most interesting materials are those with 7,7,8,8-tetracyanoquinodimethane (TCNQ) in the role of acceptor molecule.

As the structural and magnetic properties of these anion-radical salts (ARS) are strongly dependent on the cation present in the compound, the understanding of magneto-structural correlations is crucial for any further practical applications. In our previous work, the thermodynamic and magnetic properties of several genuineorganic and metal-organic ARS systems were studied [1].

The electron paramagnetic resonance (EPR) provides wide options for the study of magnetic excitations and spin states. Despite its single operating frequency, the $\mathrm{X}$-band EPR spectrometer is a great tool for the examination of the influence of weak anisotropy or magnetic interaction on magnetic properties of molecular and lowdimensional magnets thanks to its high resolution and sensitivity.

In this paper we present the comparison study of the shape of the spectra, $g$-factors and linewidths obtained on [Me-2,6-di-Me-Py](TCNQ) $)_{2}$, [Me-3,5-di-Me$\mathrm{Py}](\mathrm{TCNQ})_{2}$, [N-Me-OH-Me-Py](TCNQ) ${ }_{2}$ and [N-Et$\mathrm{OH}-\mathrm{Me}-\mathrm{Py}](\mathrm{TCNQ})_{2}$ genuine-organic ARS and [Mnphen $\left._{3}\right](\mathrm{TCNQ})_{2} \cdot \mathrm{H}_{2} \mathrm{O}$ metal-organic ARS.

\section{Experimental techniques}

The measurements were conducted using Bruker ELEXSYS E500 X-band spectrometer with operating frequency of $9.4 \mathrm{GHz}$ equipped with ESR910 flow-type cryostat. The measurements were performed in the temperature range from $2 \mathrm{~K}$ to $300 \mathrm{~K}$. All samples in form of

*corresponding author; e-mail: martin.botko@student.upjs.sk powder were mixed with Apiezon $\mathrm{N}$ grease and attached to the Suprasil sample holder.

\section{Results and discussion}

Although the genuine-organic ARS [Me-2,6-di-Me$\mathrm{Py}](\mathrm{TCNQ})_{2}$ and [Me-3,5-di-Me-Py](TCNQ) 2 are very similar from the chemical point of view (cation molecules are isomers), their crystal structure differs significantly, giving rise to different magnetic structures of these compounds. While magnetic properties of [Me-2,6-di-Me$\mathrm{Py}](\mathrm{TCNQ})_{2}$ can be described by the model of linear antiferromagnetic Heisenberg spin chain with small amount of free spins [2], the magnetism of [Me-3,5di-Me-Py] $(\mathrm{TCNQ})_{2}$ is best represented by the two-gap model [1].

The study of EPR spectra of [Me-2,6-di-Me$\mathrm{Py}](\mathrm{TCNQ})_{2}$ and [Me-3,5-di-Me-Py](TCNQ) $)_{2}$ revealed single resonance located at $g=2.0028$ and $g=2.0032$ respectively (Fig. 1). The values of $g$-factor are near to those of the unpaired electron, which is in good agreement with expected electronic structure of the materials [3].

Considerable decrease of linewidth along with the occurrence of structure in the resonance was observed with the increasing temperature (Fig. 1, inset), which could be attributed to the presence of anisotropic value of $g$-factor.

The examination of EPR spectra of another pair of ARS with similar chemical composition, the [N-Et-OH$\mathrm{Me}-\mathrm{Py}](\mathrm{TCNQ})_{2}$ and [N-Me-OH-Me-Py](TCNQ) ${ }_{2}$, revealed very different shape of resonance lines. The EPR spectrum of [N-Et-OH-Me-Py] (TCNQ $)_{2}$ has a single resonance at $g=2.0025$ (Fig. 2) and reveals no additional anisotropy with increasing temperature. On the other hand, the EPR spectrum of [N-Me-OH-Me-Py](TCNQ) 2 is anisotropic even at low temperatures (Fig. 2), with the following values of $g$-factors: $g_{x}=1.9668, g_{y}=2.0021$ and $g_{z}=2.0035$. This could indicate the influence of methyl group in cation molecule on the spatial distribution of charge in TCNQ molecules, causing the anisotropy of $g$-factor, while ethyl groups have no such effect. 


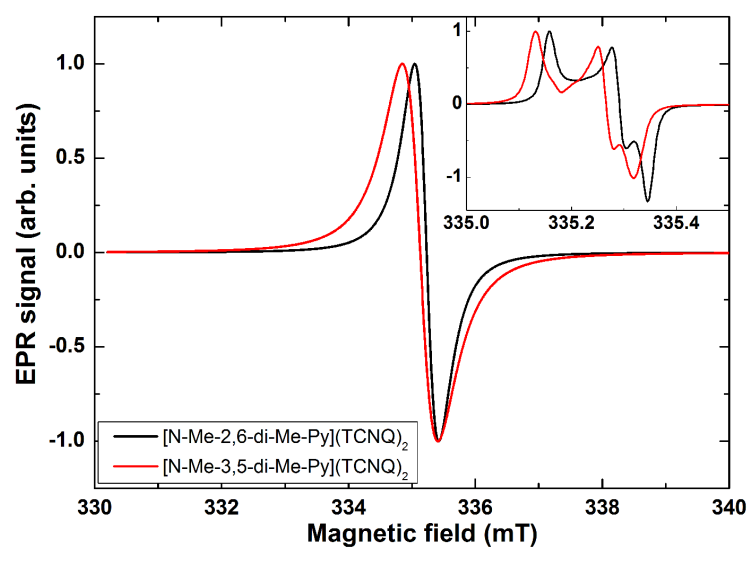

Fig. 1. EPR spectra of genuine-organic ARS [Me-2,6di-Me-Py] (TCNQ $)_{2}$ and [Me-3,5-di-Me-Py](TCNQ $)_{2}$ at $T=2 \mathrm{~K}$ and $T=30 \mathrm{~K}$ (inset).

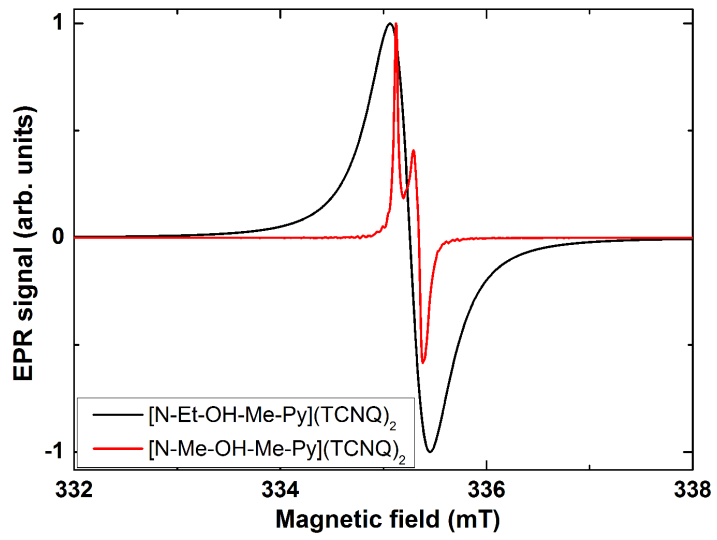

Fig. 2. EPR spectra of genuine-organic ARS [N-Et$\mathrm{OH}-\mathrm{Me}-\mathrm{Py}](\mathrm{TCNQ})_{2}$ and [N-Me-OH-Me-Py](TCNQ) $)_{2}$ at $T=2 \mathrm{~K}$

The study of magnetic properties and EPR spectra of metal-organic ARS is more complicated due to the mixed origin of magnetism in such compounds. While in genuine-organic ARS the magnetism arises from presence of $\pi$-binding orbitals between the TCNQ anions (and the charge they carry), the cation with metal ion contributes to magnetism in metal-organic ARS as well.

In our study of EPR spectra of [Mnphen $\left._{3}\right](\mathrm{TCNQ})_{2} \cdot \mathrm{H}_{2} \mathrm{O}$ we have observed strong resonance with $g=2.06$ at $T=2.1 \mathrm{~K}$ and small additional signal at higher value of $g$-factor (Fig. 3 ), which vanishes at higher temperatures. The linewidth is considerably larger than the typical one for genuine-organic ARS and the signal intensity significantly decreases with increasing temperature. This behavior suggests that the resonance originates from $\mathrm{Mn}^{2+}$ ions. We were able to simulate the spectra qualitatively (Fig. 3) for $S=5 / 2$ manganese ions, including small single-ion anisotropy $D=-0.04 \mathrm{~K}$ using EASYSPIN simulation package [4].
A hyperfine splitting of the resonance line was not resolved due to large linewidth and was not included in the simulation.

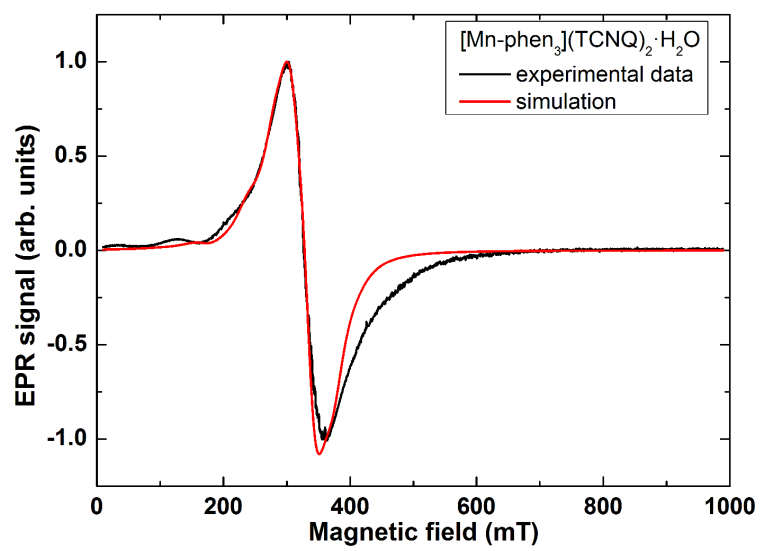

Fig. 3. EPR spectra of metal-organic ARS [Mnphen $\left._{3}\right](\mathrm{TCNQ})_{2} \cdot \mathrm{H}_{2} \mathrm{O}$ and simulation of the spectra, which included single-ion anisotropy for $S=5 / 2$ manganese ions.

\section{Conclusions}

The studied EPR spectra of the genuine-organic ARS showed that $g$-factors for all samples are very close to value for one unpaired electron, which is in agreement with the results of quantum-chemical calculations for these compounds. Slight differences in obtained $g$-factors indicate negligible contribution of donor molecules.

EPR spectra of metal-organic ARS showed higher deviation of $g$-factor as well as considerably larger linewidth, indicating the undisputed contribution of cation to magnetism of the material.

\section{Acknowledgments}

This work was supported by the SAS Centre of Excellence CFNT MVEP, by the ERDF EU grant under the contract No. ITMS26220120047, and by the Slovak Research and Development Agency under the contract APVV-0132-11. The financial support of U. S. Steel Košice is gratefully acknowledged.

\section{References}

[1] A. Radváková, O.N. Kazheva, A.N. Chekhlov, O.A. Dyachenko, M. Kucmin, M. Kajňaková, A. Feher, V.A. Starodub, J. Phys. Chem. Solids 71, 752 (2010).

[2] M. Botko, V.O. Cheranovskii, O.N. Kazheva, G.V. Shilov, O.A. Dyachenko, A.B. Verkin, M. Kucmin, V.A. Starodub, A. Radváková, M. Kajňaková, A. Feher, Solid State Sci. 24, 85 (2013).

[3] J. Kürti, G. Menczel, Phys. Status Solidi B 102, 639 (1980).

[4] S. Stoll, A. Schweiger, J. Magn. Reson. 178, 42 (2006). 